\title{
Body height and its estimation utilizing arm span measurements in population of Birgunj Area of Nepal: An Anthropometric study
}

\author{
RP Sah ${ }^{1}$, A kumar², RK Bhaskar ${ }^{3}$ \\ ${ }^{1}$ Department of Anatomy, MB Kedia Dental College, Birgunj \\ ${ }^{2}$ Department of Anatomy, National Medical College, Birgunj, Nepal \\ ${ }^{3}$ Department of Community Medicine, , National Medical College, Birgunj, Nepal
}

\section{ABSTRACT}

\section{Bacground}

Arm span is the most reliable anthropometric measurement to predict the stature of an individual. Age and sex have to be taken into account to the best to predict height from arm span. It is useful in predicting age related loss in stature and in identifying individuals with disproportionate growth abnormalities and skeletal dysplasia.

\section{Objective}

The present study was under taken to measure the stature as well as arm span and to determine whether there is any correlation between the stature and the arm span

\section{Method}

This cross sectional type of descriptive study was carried out with a total number of 400 Nepalese adult population consisting of 225 Nepalese male adults and 175 female adults aged between 25 to 45 years. Stature and arm span were measured directly from the subjects by using anthropometric technique by a measuring tape. The data taken were statistically analyzed by computation to find out its normative value. The relationship between body height and arm span were determined using simple correlation coefficients. Then a linear regression analysis was performed to examine the extent to which arm span can readily predict body height

\section{Results}

The results have shown male of Birgunj are $167.39 \pm 6.170 \mathrm{~cm}$ tall and have arm span of $168.01 \pm 7.659$ $\mathrm{cm}$, while female of Birgunj are $155.61 \pm 6.894 \mathrm{~cm}$ and have arm span of $159.25 \pm 6 . .362 \mathrm{~cm}$. The results obtained are substantially alike in other populations, since arm span was too close to body heights in male and greater in female.

\section{Conclusion}

The body height and arm span correlates well in males but not in females. This confirms the necessity for developing separate height models for each population and different sex. 
Journal of College of Medical Sciences-Nepal, 2013, Vol-9, No-4,

\section{INTRODUCTION}

It is well known in scientific literature that the measurement of body height is important in many settings: it is an important measure of body size and gives an assessment of nutritional status. ${ }^{1}$ as well as an important measure of determination of basic energy requirements, standardization of measures of physical capacity and adjusting drug dosage, and evaluation of children's growth, prediction and standardization of physiological variables such as lung volumes, muscle strength, glomerular filtration and metabolic rate etc. . $3,3^{3}$ However, the exact body height cannot always be determined the usual way because of various deformities of the extremities or in patients who have undergone amputations or similar injuries. In such circumstances, an estimate of body height has to be derived from other reliable anthropometric indicators, such as hand and foot lengths ${ }^{5,6}$ sitting height and knee height ${ }^{7,8}$ length of the sternum, ${ }^{9}$ vertebral column length, ${ }^{10}$ length of scapula, ${ }^{11}$ arm $\operatorname{span}^{12,13}$ as well as cranial sutures ${ }^{14}$ etc. Therefore, all these anthropometric indicators that are used as an alternative to estimate body height are very important in predicting age-related loss in body height, for example, in identifying individuals with disproportionate growth abnormalities and skeletal dysplasia or body height loss during surgical procedures on the spine, ${ }^{3}$ as well as predicting body height in many older people, as it is very difficult to measure it precisely, and sometimes impossible because of mobility problems and kyphosis. ${ }^{8}$ Several studies have reported the effectiveness and reliability of using various body parameters in predicting body height and arm span. ${ }^{8,13}$ Even though several studies of this nature are available on western and Indian population but very limited data on Nepalese population. So, the purpose of this study was to examine the body height in both sexes of Nepalese population of Birgunj, and the relationship between arm span and body height.

\section{METHODS}

The study was basically observational, crosssectional and descriptive in nature. The study was carried out on 225 adult males and 175 adult females from Birgunj, Nepal throughout a period of two months from January to March in 2012. The population were randomly selected to be included in this study. The average age of male was 29.91土 6.734 (range $21-45$ years) and female was age $32.31 \pm 5.256$ (range 23-45 years). This age group was chosen because the growth of an individual ceases by this age and there is no age related loss in body height at this age. Informed verbal consent was obtained. Subjects possessing skeletal deformities, physical disabilities, past history of skeletal injuries or diseases affecting bones and joints and subjects who are on any form of hormonal medications were excluded from the study. The subjects were said to stand with her heel together and her backs straight as possible so that her heels, buttocks, shoulders and the head touched the wall. The arms were hung freely by the sides with the palm facing the thighs. After asking the subject to take a deep breath and holding it, a measuring scale (steel plate) was placed against the head and wall to determine maximum height on the wall, and this was marked. The subject was then told to breathe and to step away from the wall. The height was then measured from the floor to the mark on the wall with steel tape which represents the stature in centimeters to the nearest 0.1 centimeters. Arm span was measured with a flexible steel tape from the tip of the middle finger on one hand to the tip of the middle finger on the other hand with the individual standing with her back to the wall with both arms abducted to $90^{\circ}$,the 
Body Height and Its Estimation Utilizing Arm Span Measurements in.

elbows and wrists extended and the palms facing directly forward (Figure 1). Readings were taken to the nearest 0.1 centimeters. Each subject was measured twice. When the two measurements for each parameter agreed within 0.4 centimeters, their

Fig.-1 Procedure of measuring the arm span

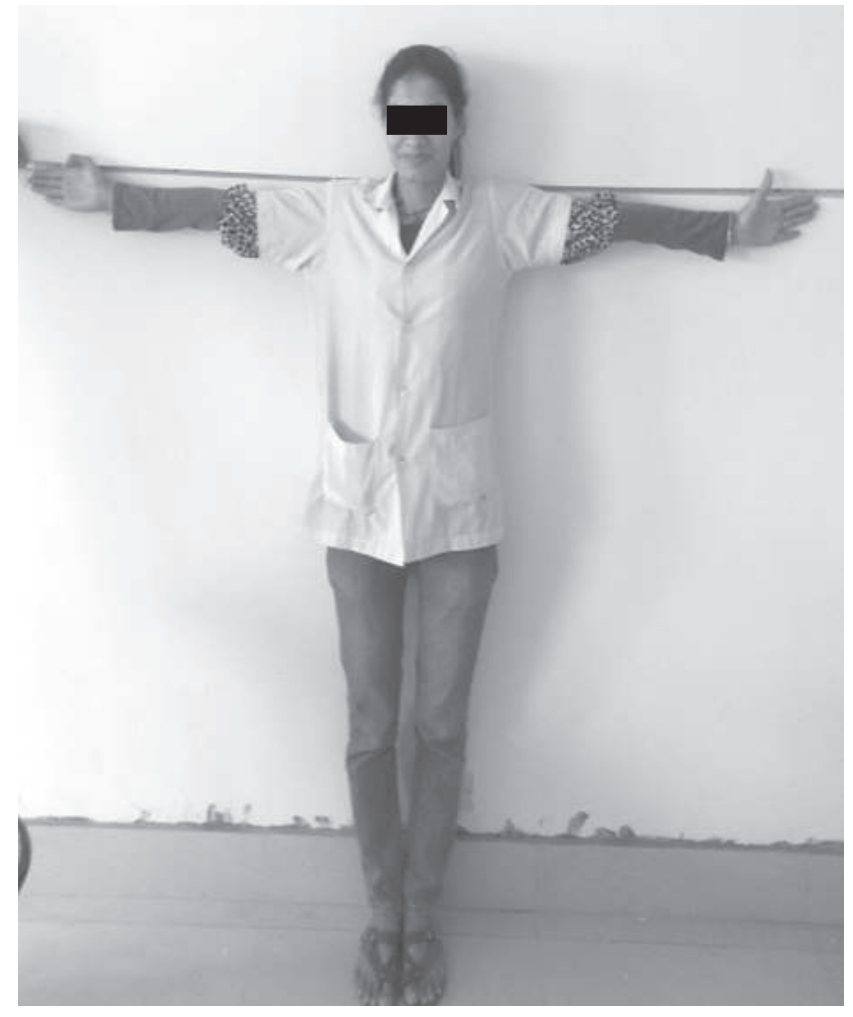

\section{Statistical Analysis}

The analysis was carried out using a computer based programmed (SPSS version-11.5 \&MS Excel). Mean and standard deviations were obtained for both anthropometric variables. The relationships between body height and arm span were determined using simple correlation coefficients. Then a linear regression analysis was performed to examine the extent to which arm span can reliably predict body height. Finally, these relationships were plotted as scatter diagram. Statistical significance was set at $\mathrm{p}<0.05$. average was taken as the best estimate for the true value. When the two initial measures did not satisfy the 0.4 centimeters criterion, two additional determinations were made and the mean of the closest records was used as the best estimate.

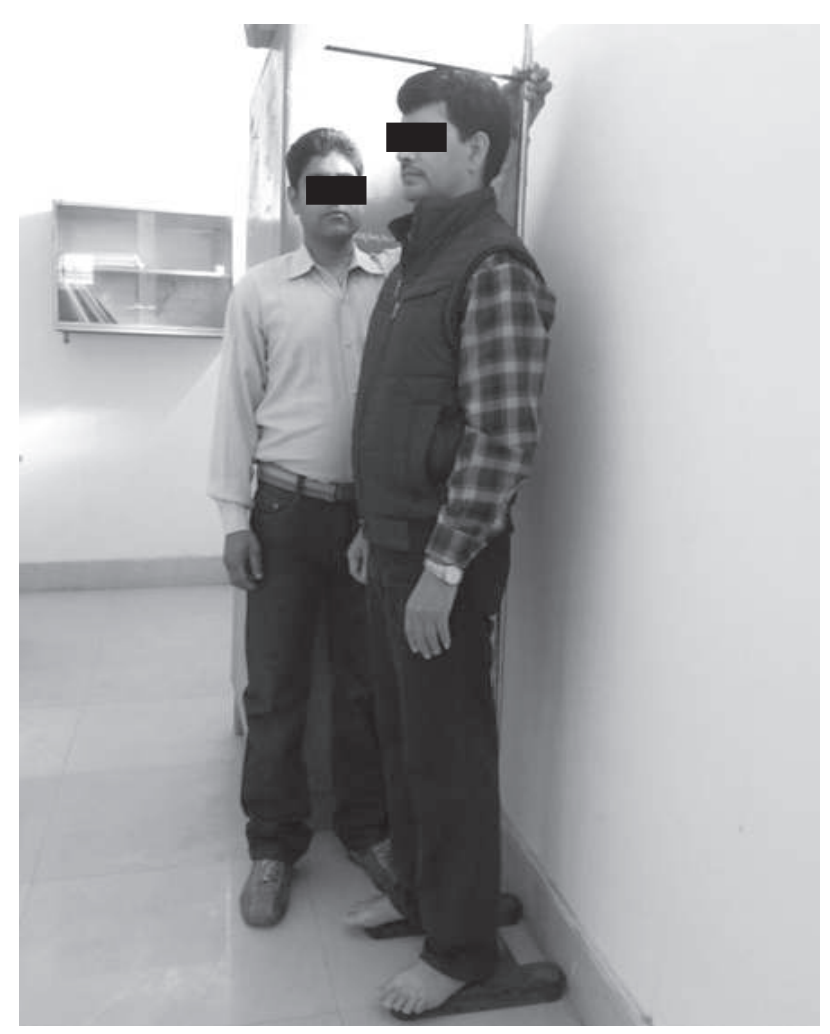

\section{RESULTS}

A summary of the anthropometric measurements in both sexes is shown in Table 1. The mean of the arm span and body height of male subjects was found to be approximately equal and for female subject the arm span was greater than body height. The simple correlation coefficient and their statistically tested significance are presented in Table 2. The relationships between body height and arm span are high and significant in the sample, regardless of sex.

The results of linear regression analysis are shown in Table 3.The high values of the regression coefficient signify that arm span significantly predicts body height in both sexes. 
Journal of College of Medical Sciences-Nepal, 2013, Vol-9, No-4,

Table 1 Anthropometric measurement of the study subjects

\begin{tabular}{|ccccc|} 
Subjects & $\begin{array}{c}\text { Body height } \\
\text { range }(\mathbf{c m})\end{array}$ & $\begin{array}{c}\text { Body height } \\
(\text { Mean } \pm \text { SD) }(\mathbf{c m})\end{array}$ & $\begin{array}{c}\text { Arm span } \\
\text { range }(\mathbf{c m})\end{array}$ & $\begin{array}{c}\text { Arm span } \\
(\text { Mean } \pm \text { SD) }(\mathbf{c m})\end{array}$ \\
\hline Male & $142-178$ & $167.39 \pm 6.17$ & $141-184$ & $168.01 \pm 7.65$ \\
\hline Female & $142-176$ & $155.61 \pm 6.89$ & $141-170$ & $159.25 \pm 6.36$ \\
\hline
\end{tabular}

Table 2 Correlation between body height and arm span of the study subject

$\begin{array}{lcc}\text { Subjects } & \text { Correlation coefficient } & \text { Significance p-value } \\ \text { Male } & 0.682 & <0.001 \\ \text { Female } & 0.507 & <0.001\end{array}$

Table 3. Results of linear regression analysis where the arm span predicts the body height

$\begin{array}{lccccc}\text { Subjects } & \begin{array}{c}\text { Regression } \\ \text { coefficient }\end{array} & \begin{array}{c}\text { Standard } \\ \text { error }\end{array} & \text { R-square }(\boldsymbol{\%}) & \text { t-value } & \text { p-value } \\ \text { Male } & 0.682 & 0.039 & 75.077 & 11.314 & <0.001 \\ \text { Female } & 0.507 & 0.071 & 68.054 & 7.743 & <0.001\end{array}$

The relationship between arm span measurements and body height among the above model is plotted as a scatter diagram shown in figure 2 .

Fig2: Scatter diagram and relationship between arm span measurements and body height among both sexes.

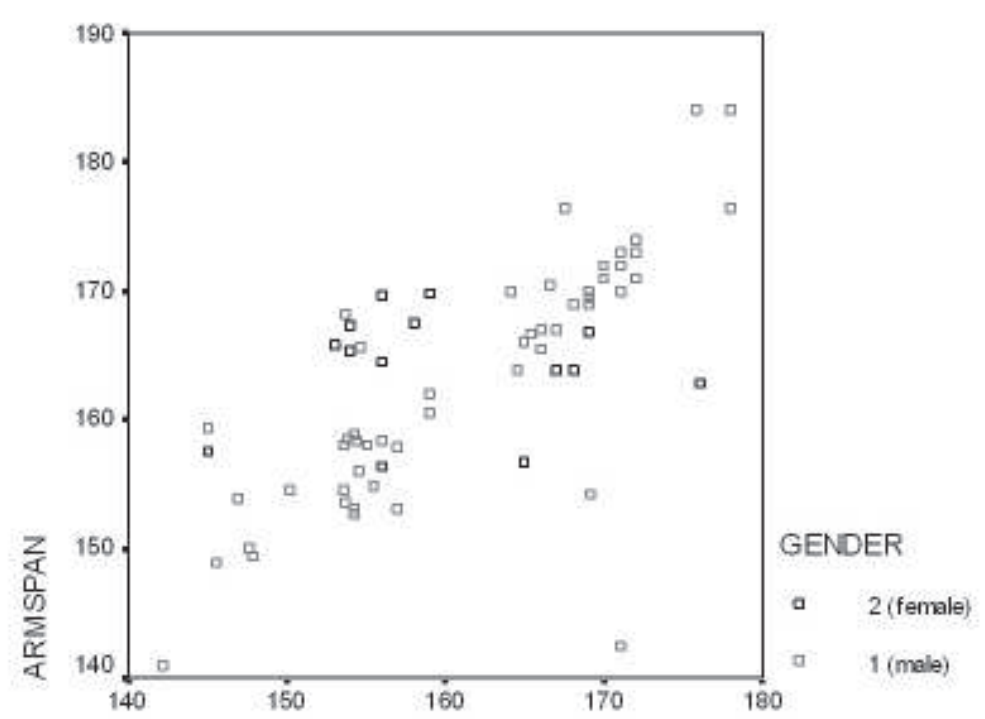

HEIGHT 
Body Height and Its Estimation Utilizing Arm Span Measurements in.

\section{DISCUSSION}

The estimation of body height using various anthropometric measurements has attempted by many authors in many studies over the centuries. As already mentioned, all of them estimated body height from various anthropometric measurements, but it is important to emphasize that the arm span has been derived the most reliable body indicator for predicting the body height of an individual., ${ }^{3,13}$ However, individual and ethnic variations in respect of body height and its relation with arm span were already observed in European ${ }^{15}$ and African populations. ${ }^{16}$ The arm span was nearly 8.3 centimeters more than the body height for the black population (105.36\% body height), whereas for the white population this difference was only 3.3 centimeters (102.04\% body height). ${ }^{17}$ The arm span was nearly 2.5 centimeters more than the body height in South Indian females $(101.4 \%$ body height), which is similar to that noted in the white population. ${ }^{3}$ The arm span was 5.8 centimeters more than body height for Nigerian males (103.3\% body height), whereas for Nigerian females this difference was only 4 centimeters $(102.5 \%$ body height) which is similar to that noted in the white population. ${ }^{13}$

Therefore, the main goal of the present study was to find out if these facts are true for the Nepalese population especially residing in Birgunj area, since it is known that the estimating equation varies from race to race, and ethnic group to ethnic group. ${ }^{3}$ Hence, in the present study it was observed that the arm span was nearly same to the body height in males, while it was 3.64 centimeters less than the body height in Nepalese female population. As the correlation between arm span and body height was modest and significant in both Nepalese sexes, the arm span measure therefore seems to be a reliable indirect anthropometric measurement for estimating body height in adults. The result of our study is similar to that of study carried out by previous researchers.

\section{CONCLUSION}

The population of Birgunj area have different ethnic groups and their different economical status affect nutritional status affecting growth of body. This study suggests to study more precisely on different ethnic groups as many people from various parts have migrated to Birgunj city in search of better lives and infrastructures. Therefore, it is necessary to develop separate models for each population, on account of ethnic differences, using bigger samples for the prediction of body height utilizing arm span measurement. A more precise estimation of the average body height and its prediction utilizing arm span measurements in Nepalese adults would require a larger sample with sufficient geographical and social heterogeneity or a national survey that measures the whole population. Thus, the obvious limitation of this research study was the composition of the measured sample that consisted of population from different societies.

\section{ACKNOWLEDGEMENT}

The authors are grateful to all the faculty members of the respective departments and to the Managing Director of Shree Bhawani Hospital and Research Center (P) Ltd.,Link Road,Birgunj for their guidance and supports. 


\section{REFERENCES}

1. Datta B, Sudip. Arm span as a proxy measure for height and estimation of nutritional status: A studyamong Dhimals of Darjeeling in West Bengal India. Annals of Human Biology 2011;38(6): 728-35.

2. Mohammad G, Amra B \& M. A. Hoghogi M.A. 2003. Is arm span an accurate measure of height to predict pulmonary function parameters? Monaldi Archives for Chest Disease2003; 59(3): 189-92

3. Mohanty S.P.,Sreekumaran Nair S. S.B\&S. The use of arm span as a predictor of height. A study of South Indian women. Journal of Orthopedics Surgery2001; 9(1): 19-23

4. Daniel T.G., Toriola A.L., Musa D.I. \& Akusu S. The relationship between arm span and stature in Nigerian adults. Kinesiology2011; 43(1): 38-4

5. Agnihotri K, Smriti Agnihotri S, Jeebun N \& GoogoolyeK. 2008. Prediction of stature using hand dimensions. Journal of Forensic and Legal Medicine.2008; 15(8): 479-82.

6. Tanuj K, Menezes R, Moudgil R, Kaur R, Kotian M.S. \& Garg R. . Stature estimation from foot dimensions. Forensic Science International. 2008;179(2-3): 241e1-241e

7. Fatmah.Validation of predicted height model based on arm span, knee height and sitting height in Indonesian elderly people. Journal of Clinical Medicine and Research. 2010;2(5): 67-73.

8. Mary H \& Frost G. 2003. A comparison of three methods for estimating height in the acutely ill elderly population. Journal of Human Nutrition and Dietitics.2003; 16(1): 13-20.

9. Menezes R, Kanchan T, Kuma P, Rao J, Lobo S, Uysa S, Krishan K, Kalthur S, K.
Nagesh K.K. \& Shettigar S. Stature estimation from the length of the sternum in South Indian males: A preliminary study. Journal of Forensic and Legal Medicine.2009; 16(8): 441-3.

10. Nagesh, K. R. \& Kumar P. . Estimation of stature from vertebral column length in South Indians. Legal Medicine.2006; 8(5): 269-7

11. Carlo C, Di-Vella G \& Introna F. 1998. Using scapular measurements in regression formulae for the estimation of stature. Bollettino dellà Societa Italiana di Biologia Sperimentale.1998; 74(7-8): 75-82.

12 Peter J \& Gledhill R. Predicting height from arm span measurements. Journal of Pediatric Orthopedics.1993 13(6): 761-5.

12. Danie T.G. Toriola A.L., Ibrahim D, Musa \& Akusu S. 2011. The relationship between arm span and stature in Nigerian adults. Kinesiology.2011; 43(1): 38-43.

13. Rao J , Sowmya J, K. Yoganarasimha R. Menezes,T, Kanchan \& Aswinidutt A. 2009. Estimation of stature from cranial sutures in a South Indian male population. International Journal of Legal Medicine.2009; 123(3): 2716.

14. Leander R, Varakamin C \& Henry J. 1996. The relationship between arm-span measurements and height with special reference to gender and ethnicity. European Journal of Clinical Nutrition.1996; 50(6): 398-400.

15. Rolfe D.L, Lemma E.F.,Tesfaye F, Demisse T \& Ismail S. 2002. The use of armspan measurement to assess the nutritional status of adults in four Ethiopian ethnic groups. European Journal of Clinical Nutrition.2002; 56(2): 91

16 Marilyn S \& Chenier T. 1990. Arm-span, height and age in black and white women. Annals of Human Biology.1990; 17(6): 533-41. 